\title{
Anti-Glycation and Glycation Reversing Potential of Fenugreek (Trigonella Foenum-Graecum) Seed Extract
}

\author{
Abeysekera $\mathrm{WKSM}^{* 1,2}$, Abayarathna UPTC ${ }^{3}$, Premakumara $\mathrm{GAS}^{2}$, Jayasooriya $\mathrm{MCN}^{3}$ and Abeysekera \\ WPKM $^{2}$
}

${ }^{1}$ Department of Agricultural Technology, University of Colombo, Sri Lanka

${ }^{2}$ Modern Research \& Development Complex (MRDC), Industrial Technology Institute (ITI), Sri Lanka

${ }^{3}$ Department of Food Science \& Technology, Sabaragamuwa University of Sri Lanka, Sri lanka

Received: March 01,2018; Published: March 20, 2018

*Corresponding author: WKSM Abeysekera, Department of Agricultural Technology, University of Colombo, Sri Lanka, Tel: 94-11-2078614;

Email: kanchana@at.cmb.ac.lk

Abstract

Aim: To evaluate the anti-glycation and glycation reversing potential of fenugreek seed extract.

Methods: Freeze dried 70\% ethanolic seed extract of fenugreek was used in this study. Anti-lycation and glycation reversing potential was studied in Bovine serum albumin (BSA)-glucose model. Antioxidant properties were studied using total polyphenolic content, total flavonoid content, 2,2'-azino-bis(3-ethylbenzothiazoline-6-sulfonic acid (ABTS),1,1-diphenyl-2-picrylhydrazine (DPPH) and ferric reducing antioxidant power (FRAP) in vitro antioxidant assays.

Results: The results demonstrated significant $(\mathrm{P}<0.05)$ and dose dependant anti-glycation [IC50: $(147.99 \pm 3.94) \mu \mathrm{g} / \mathrm{mL}]$ and glycation reversing activities [EC50:(553.37 \pm 8.02$) \mu \mathrm{g} / \mathrm{mL}$ ] and marked antioxidant properties [total polyphenolic content: $(43.67 \pm 2.85) \mathrm{mg}$ gallic acid equivalents/g of extract; total flavonoid content: $(25.25 \pm 0.91) \mathrm{mg}$ quercetin equivalents/g of extract; 2,2'-azino-bis(3-ethylbenzothiazoline-6sulfonic acid (ABTS), 1,1-diphenyl-2-picrylhydrazine (DPPH) and ferric reducing antioxidant power (FRAP): $(35.45 \pm 0.32),(28.13 \pm 0.76)$ and (21.06 \pm 0.42$) \mathrm{mg}$ Trolox equivalents/g of extract, respectively].

Conclusion: Seed extract of fenugreek had both anti-glycation and glycation reversing activities in BSA-glucose glycation model. Glycation reversing activity of fenugreek seed extract is a novel finding having therapeutic potentials. Thus, findings of this study indicate usefulness of fenugreek seed in managing advanced glycation end products associated pathologies in diabetes.

Keywords: Anti-Glycation; Glycation Reversing; Antioxidant Activity; Advanced Glycation End Products; Diabetes Complications; Fenugreek; Seed Extract

Abbreviations: BSA: Bovine Serum Albumin; FRAP: Ferric Reducing Antioxidant Power; DPPH: Diphenyl Picrylhydrazine; ABTS: Azino-Bis Ethylbenzothiazoline Sulfonic Acid; AGEs: Advanced Glycation End Products; TPC: Total Polyphenolic Content; GAC: Gallic Acid Equivalents; TE: Trolox Equivalents; DMRT: Duncan's Multiple Range Test

\section{Introduction}

Diabetes is a chronic metabolic disorder and rapidly increasing worldwide in both developed and developing countries [1,2]. The global prevalence of diabetes in 2000was $2.8 \%$ representing 171 million people worldwide and it was predicted to rise up to $4.4 \%$ representing 366 million people for 2030 [3]. However, recent diabetes statistics has shown that the worldwide prevalence of diabetes in 2014 was $8.3 \%$ representing 387 million people which are even higher than the predication for 2030. Further, this number is projected to increase by another 205 million people in
2035 [2]. According to the most recent findings by International Diabetes Federation there were 425 million people with diabetes in year 2017 and number is projected to be 629 million people with diabetes in 2045 [4]. The complications of diabetes lead to both morbidity and mortality. Such deliberating diabetes complications include peripheral neuropathy, nephropathy, retinopathy, vascular damage, atherosclerosis, decreased myocardial compliances and impaired wound healing [5-8]. These complications are facilitated through a well known reaction named as protein glycation. It's a 
series of non-enzymatic complex reactions between reducing sugars and proteins which lead to generate multitude of glycation end products [5-8].

It is scientifically well proven that formation and accumulation of glycation products especially advanced glycation end products (AGEs) play a vital role in the development and progression of deleterious diabetes complications. Thus, glycation inhibitors and glycation reversing agents offer a potential strategy as therapeutics for management of diabetes and its complications [5-8]. Natural products have been used in the management of diabetes since ancient times. Fenugreek (Trigonella foenum-graecum) is an annual plant which belongs to the family Leguminosae is one of the oldest spice thought the world [9-11]. Fenugreek seed is well known for various medicinal properties including anti-diabetic properties world over [9-11]. The anti-diabetic properties of fenugreek seed have been shown in both in vitro and in vivo models covering various modes of actions [9-11]. However, the effect of fenugreek seed extracts on anti-glycation activity is limitedly studied. Further, there are no previous reports on effect of fenugreek seed extracts on glycation reversing ability which is one of the most important aspects in the management of diabetes complications. Therefore, this study investigated anti-glycation and glycation reversing ability of fenugreek seed extract.

\section{Materials and Methods}

\section{Fenugreek Seed Sample and Preparation of Extract}

Fenugreek seeds purchased from local market were used in this study. Seventeen grams of fenugreek seed flour was extracted in $200 \mathrm{~mL}$ of $70 \%$ ethanol- water (v/v). The extraction was carried out for $16 \mathrm{~h}$ at room temperature $\left(30 \pm 2^{\circ} \mathrm{C}\right)$ at $150 \mathrm{rpm}$ using an orbital shaker. The sample was then centrifuged at $3500 \mathrm{rpm}$ for $5 \mathrm{~min}$ and the resulting supernatant was evaporated using a rotary evaporator with low pressure at $45^{\circ} \mathrm{C}$ and freeze dried.

\section{Chemicals and Reagents}

Bovine serum albumin (BSA), D-glucose, Trolox, 1,1-diphenyl2-picrylhydrazine (DPPH),2,2'-azino-bis(3-ethylbenzothiazoline-6sulfonic acid) diammonium salt (ABTS), 2,4,6-tripyridyl-s-triazine (TPTZ), potassium persulfate, gallic acid, trichloroacetic acid (TCA) and Folin-Ciocalteu phenol reagentwere purchased from SigmaAldrich, USA. All the other chemicals used for the preparation of buffers and solvents were of analytical grade.

\section{Anti-Glycation Activity}

The anti-glycation activity of fenugreek seed extract was performed according to the method of Matsuura et al. [12]. With some modifications, Reaction volume of $1 \mathrm{~mL}$ containing 800 $\mu \mathrm{g}$ BSA, $400 \mathrm{mM}$ glucose and fenugreek seed extract $(12.5,25$, $50,100,200,400 \mu \mathrm{g} / \mathrm{mL} ; \mathrm{n}=3)$ in $50 \mathrm{mM}$ phosphate buffer $(\mathrm{pH}$ 7.4) containing $0.02 \%$ sodium azide $(\mathrm{w} / \mathrm{v})$ were incubated at 60 ${ }^{\circ} \mathrm{C}$ for $40 \mathrm{~h}$. Then, $600 \mu \mathrm{L}$ of each sample were transferred to 1.5 $\mathrm{mL}$ eppendorf tubes and added with $60 \mu \mathrm{L}$ of $100 \%(\mathrm{w} / \mathrm{v}) \mathrm{TCA}$. Samples were then centrifuged at $15,000 \mathrm{rpm}$ at $4 \stackrel{\circ}{\circ} \mathrm{C}$ for $4 \mathrm{~min}$ and the supernatants were removed. The resulting AGEs (advanced glycation end-products)-BSA precipitate was dissolved in $3 \mathrm{~mL}$ of phosphate buffer saline ( $\mathrm{pH} 10)$ and fluorescence intensity was measured at an excitation wave length of $370 \mathrm{~nm}$ and emission wave length of $440 \mathrm{~nm}$ using a 96-well florescence micro plate reader (SPECTRA max- Gemini EM, Molecular Devices Inc, USA). Rutin was used as the standard (positive control). Anti-glycation activity (inhibition \%) of fenugreek seed extract and rutin was calculated using the following equation.

$$
\text { Inhibition }(\%)=\left[\left(F_{c}-F_{b}\right)-\left(F_{s}-F_{s b}\right) /\left(F_{c}-F_{b}\right)\right] * 100
$$

Where, $F_{c}$ is the florescence of incubated BSA and glucose (control), $\mathrm{F}_{\mathrm{b}}$ is the florescence of incubated BSA alone (blank), Fs is the florescence of the incubated BSA, glucose and fenugreek seed extract or the positive control and $\mathrm{F}_{\mathrm{sb}}$ is the florescence of incubated BSA with the fenugreek seed extractor the positive control.

\section{Glycation Reversing Ability}

The glycation reversing ability of fenugreek seed extract was performed according to the method of Premakumara et al [13]. with some modifications. Reaction volume of $1 \mathrm{~mL}$ containing 800 $\mu \mathrm{g}$ BSA and $400 \mathrm{mM}$ glucose in $50 \mathrm{mM}$ phosphate buffer ( $\mathrm{pH} 7.4$ ) containing $0.02 \%$ sodium aside $(\mathrm{w} / \mathrm{v})$ was incubated at $60 \stackrel{\mathrm{o}}{\mathrm{C}}$ for $40 \mathrm{~h}$. Then, aliquots of $600 \mu \mathrm{L}$ were transferred to $1.5 \mathrm{~mL}$ eppendorf tubes and $60 \mu \mathrm{L}$ of $100 \%(\mathrm{w} / \mathrm{v})$ TCA was added. Samples were then centrifuged $(15,000 \mathrm{rpm})$ at $4{ }^{\circ} \mathrm{C}$ for $4 \mathrm{~min}$ and the supernatants were removed. The resulting AGEs-BSA precipitates were dissolved in $50 \mathrm{mM}$ phosphate buffer (pH 7.4) and added with 75, 150, 300, $600 \mu \mathrm{g} / \mathrm{mL}$ fenugreek seed extract $(\mathrm{n}=3)$ in a final reaction volume of $1 \mathrm{~mL}$ for incubation at $60{ }^{\circ} \mathrm{C}$ for $40 \mathrm{~h}$. After cooling, $60 \mu \mathrm{L}$ of $100 \%(\mathrm{w} / \mathrm{v})$ TCA was added, stirred and centrifuged $(15,000 \mathrm{rpm})$ at $4 \stackrel{\circ}{\circ} \mathrm{C}$ for $4 \mathrm{~min}$. The resulting precipitates were dissolved in $3 \mathrm{~mL}$ of phosphate buffer saline (pH 10) and the fluorescence intensity was measured at an excitation wave length of $370 \mathrm{~nm}$ and emission wave length of $440 \mathrm{~nm}$ using a96-well florescence micro plate reader (SPECTRA max- Gemini EM, Molecular Devices Inc, USA). Percentage glycation reversing was calculated using the following equation.

$$
\text { Glycation reversing }(\%)=\left[\left(F_{c}-F_{b}\right)-\left(F_{s}-F_{s b}\right) /\left(F_{c}-F_{b}\right)\right] * 100
$$

Where, $F_{c}$ is the florescence of incubated BSA and glucose (control), $\mathrm{F}_{\mathrm{b}}$ is the florescence of incubated BSA alone (blank), Fs is the florescence of the incubated BSA, glucose and fenugreek seed extract and $\mathrm{F}_{\mathrm{sb}}$ is the florescence of incubated BSA with the fenugreek seed extract.

\section{Antioxidant Properties}

Total Polyphenolic Content: The Total polyphenolic content (TPC) of fenugreek seed extract was determined according to the method of Singleton et al [14]. Using 96-well micro-plates $(n=3)$. Twenty micro liters of fenugreek seed extract $(1 \mathrm{mg} / \mathrm{mL})$ was added to $110 \mu \mathrm{L}$ of ten times diluted freshly prepared Folin-Ciocalteu reagent. Then, $70 \mu$ Lof sodium carbonate solutions was added and incubated at room temperature $(25 \pm 2 \mathrm{oC})$ for $30 \mathrm{~min}$. The absorbance readings were taken at $765 \mathrm{~nm}$ using a 96 well micro plate reader (Spectra Max Plus ${ }^{384}$, Molecular Devices, USA). Gallic acid was used to construct the standard curve. TPC was expressed as mg gallic acid equivalents (GAE)/g of fenugreek seed extract. 
Total Flavonoid Content: Total flavonoid content (TFC) of fenugreek seed extract was determined according to the method of Siddhuraju and Becker [15]. Using 96-well micro-plate $(n=3)$. Twenty five $\mu \mathrm{L}$ of $1 \mathrm{mg} / \mathrm{mL}$ fenugreek seed extract and $75 \mu \mathrm{L}$ of methanol were added and pre plate reading was taken at 415 $\mathrm{nm}$. Then, $100 \mu \mathrm{L}$ of $20 \%$ aluminum chloride solution was added and incubated at room temperature $(30 \pm 20 \mathrm{C})$ for $10 \mathrm{~min}$. The absorbance readings were taken at $415 \mathrm{~nm}$ using a 96 well micro plate reader. Quercetin was used to construct the standard curve. TFC was expressed as mg quercetin equivalents (QE)/g of fenugreek seed extract.

Ferric Reducing Antioxidant Power: Ferric reducing antioxidant power (FRAP) of fenugreek seed extract was performed according to the method of Benzie and Szeto [16]. with some modifications in 96 well micro plates $(n=3)$. The working FRAP reagent was prepared by mixing $300 \mathrm{mM}$ acetate buffer ( $\mathrm{pH}$ 3.6), 10 mM TPTZ solution and $20 \mathrm{mM} \mathrm{FeCl}_{3} \cdot 6 \mathrm{H}_{2} \mathrm{O}$ in a ratio of 10:1:1. Then the mixture was incubated at $37 \mathrm{oC}$ for $10 \mathrm{~min}$ in a shaking water bath. The TPTZ solution was prepared by making a solution of 10 $\mathrm{mM}$ TPTZ in $40 \mathrm{mM} \mathrm{HCl}$. A reaction volume of $200 \mu \mathrm{L}$, containing $150 \mu \mathrm{L}$ of working FRAP reagent, $25 \mu \mathrm{L}$ acetate buffer and $25 \mu \mathrm{L}(1$ $\mathrm{mg} / \mathrm{mL}$ ) of fenugreek extract were incubated at room temperature $(25 \pm 2 \mathrm{oC})$ for $8 \mathrm{~min}$. The absorbance readings were then taken at $600 \mathrm{~nm}$ using a 96 well micro plate reader. Trolox was used to construct the standard curve. Results were expressed as mg Trolox equivalents (TE)/g of fenugreek seed extract.

DPPH Radical Scavenging Activity: The DPPH radical scavenging activity of fenugreek seed extract was performed according to the method described by Blois [17]. In 96-well microplates $(n=3)$. A reaction volume of $200 \mu \mathrm{L}$, containing $125 \mu \mathrm{M}$ of DPPH radical, fenugreek seed extract $(25,50,100,200,400,800$ $\mu \mathrm{g} / \mathrm{mL} ; \mathrm{n}=3$ ) and methanol were incubated at $25 \pm 2 \mathrm{oC}$ for $10 \mathrm{~min}$. Then, absorbance readings were taken at $517 \mathrm{~nm}$ using a 96 well micro plate reader. Trolox was used as the standard. DPPH radical scavenging activity (inhibition \%) of fenugreek seed extract and Trolox were calculated using the following equation. Results were expressed as \% inhibition, $\mathrm{IC}_{50}$ values and $\mathrm{mg}$ Trolox equivalents/g fenugreek seed extract.

$$
\text { DPPH radical scavenging activity }(\%)=\left[\left(A_{c}-A_{s}\right) / A_{c}\right] * 100
$$

Where, $A_{c}$ is the absorbance of the control and $A_{s}$ is the absorbance of the fenugreek seed extract.

ABTS Radical Scavenging Activity: The ABTS radical scavenging activity of fenugreek seed extract was determined according to the method described by Re et al [18]. In 96-well micro-plates $(n=3)$. A stable stock solution of ABTS radical was produced by reacting $7.8 \mathrm{mM}$ of ABTS in potassium persulphate at $37 \mathrm{oC}$ for $16 \mathrm{~h}$ in dark condition. A reaction volume of $200 \mu \mathrm{L}$, containing $40 \mu \mathrm{L}$ of seven times diluted ABTS stock solution, 150 $\mu \mathrm{L}$ phosphate buffer and different concentrations of fenugreek seed extract $(6.25,12.5,25,50,100,200 \mu \mathrm{g} / \mathrm{mL} ; \mathrm{n}=3)$ were incubated at $25 \pm 2$ oC for $10 \mathrm{~min}$. Then, absorbance values were recorded at $734 \mathrm{~nm}$ using a 96 well micro plate reader. Trolox was used as the standard antioxidant. ABTS radical scavenging activity (inhibition $\%$ ) of fenugreek seed extract and Trolox were calculated using the following equation. Results were expressed as \% inhibition, IC50 values and mg Trolox equivalents/g fenugreek seed extract.

$$
\text { ABTS radical scavenging activity }(\%)=\left[\left(A_{c}-A_{s}\right) / A_{c}\right] * 100
$$

Where, $A_{c}$ is the absorbance of the control and $A_{s}$ is the absorbance of the fenugreek seed extract.

\section{Statistical Analysis}

Data of each experiment were statistically analyzed using SAS version 6.12. One way analysis of variance (ANOVA) and the Duncan's Multiple Range Test (DMRT) were used to determine the differences among treatment means.

\section{Results}

\section{Anti-Glycation Activity}

Anti-glycation activity of fenugreek seed extract is given in Table 1. As shown in fenugreek seed extract demonstrated dose dependent in vitro protein glycation inhibitory activity with an $\mathrm{IC}_{50}$ of $147.99 \pm 3.94 \mu \mathrm{g} / \mathrm{mL}$. The anti-glycation activity of fenugreek extract was moderate compared to the reference standard rutin $\left(\mathrm{IC}_{50}: 63.36 \pm 0.67 \mu \mathrm{g} / \mathrm{mL}\right.$ ) used in this study. Results are presented as mean $\pm \mathrm{SE}(\mathrm{n}=3) . \mathrm{IC}_{50}$ rutin: $21.88 \pm 2.82 \mu \mathrm{g} / \mathrm{mL}$.

Table 1: Anti-glycation activity of fenugreek seed extract.

\begin{tabular}{|c|c|}
\hline Concentration $(\boldsymbol{\mu g} / \mathbf{m L})$ & \% inhibition \\
\hline 12.5 & $1.28 \pm 4.89$ \\
\hline 25 & $3.60 \pm 6.56$ \\
\hline 50 & $7.89 \pm 5.68$ \\
\hline 100 & $42.29 \pm 6.58$ \\
\hline 200 & $66.10 \pm 8.01$ \\
\hline 400 & $80.11 \pm 5.21$ \\
\hline $\mathrm{IC}_{50}(\mu \mathrm{g} / \mathrm{mL})$ & $147.99 \pm 3.94$ \\
\hline
\end{tabular}

\section{Glycation Reversing Activity}

Glycation reversing activity of fenugreek seed extract is given in Table 2. Fenugreek seed extract showed dose dependent glycation reversing activity with an $\mathrm{EC}_{50}$ of $553.37 \pm 8.02 \mu \mathrm{g} / \mathrm{mL}$.

Table 2: Glycation reversing activity of fenugreek seed extract.

\begin{tabular}{|c|c|}
\hline Concentration $(\boldsymbol{\mu g} / \mathbf{m L})$ & \% inhibition \\
\hline 75 & $9.02 \pm 0.27$ \\
\hline 150 & $28.27 \pm 0.57$ \\
\hline 300 & $34.43 \pm 0.12$ \\
\hline 600 & $53.09 \pm 0.51$ \\
\hline $\mathrm{EC}_{50}(\mu \mathrm{g} / \mathrm{mL})$ & $553.37 \pm 8.02$ \\
\hline
\end{tabular}

Results are presented as mean \pm SE $(n=3)$.

\section{Antioxidant Properties}

Data on antioxidant activities of fenugreek seed extract is summarized in Table 3. As shown, fenugreek seed extract had considerable in vitro antioxidant activity in tested antioxidant 
assay models. Data represented as mean \pm SE. TPC: mg gallic acid equivalents/g of extract ( $\mathrm{n}=3)$; TFC: $\mathrm{mg}$ quercetin equivalents/g of extract $(n=3)$; FRAP: mg trolox equivalents/g of extract $(n=4)$; ABTS: mg Trolox equivalents/g of extract $(n=3)$; DPPH: mg Trolox equivalents/g of extract $(n=3)$.

Table 3: Antioxidant properties of fenugreek seed extract.

\begin{tabular}{|c|c|c|c|c|}
\hline \multicolumn{5}{|c|}{ Antioxidant properties } \\
\hline TPC & TFC & FRAP & ABTS & DPPH \\
\hline $43.67 \pm 2.85$ & $25.25 \pm 0.91$ & $21.06 \pm 0.42$ & $35.45 \pm 0.32$ & $28.13 \pm 0.76$ \\
\hline
\end{tabular}

\section{Discussion}

This study examined the potential of fenugreek seed extract on inhibition of protein glycation, ability to reverse glycated end products and antioxidant potential in vitro. Investigations were carried out using well established, widely used, validated, reproducible, sensitive and reliable bioassays in vitro [12-19]. BSAglucose glycation model was used since it is more relevant to the biological system of human [20]. Fenugreek seed extract was used as it is claimed to have anti-diabetic properties in the Sri Lankan traditional system of medicine [21]. and folklore. Further, there are numerous studies on anti-diabetic properties of fenugreek seed vitro and in vivo models and also in clinical studies [11]. However, protein glycation inhibitory activity of fenugreek seed is limitedly investigated. Further, glycation reversing ability of fenugreek seed is not reported to date.

The results of the present study demonstrated that fenugreek seed extract had both anti-glycation $\left(\mathrm{IC}_{50} 147.99 \pm 3.94 \mu \mathrm{g} / \mathrm{mL}\right)$ and glycation reversing $\left(\mathrm{EC}_{50} 553.37 \pm 8.02 \mu \mathrm{g} / \mathrm{mL}\right)$ activities. The ability of fenugreek seed extract to inhibit protein glycation was moderate compared to the reference drug rutin ( 6.7 fold low). Some previous studies have also confirmed the anti-glycation activity of fenugreek seed [22]. A study carried out by Moniruzzaman et al [22]. Had reported the anti-glycation activity ( $\mathrm{IC}_{50}$ values) of water and ethanolic extracts of fenugreek seed were $>200$ and $121.125 \mu \mathrm{g} /$ $\mathrm{mL}$ respectively. Further, some clinical investigations have reported that both seed and leaf extracts of fenugreek can significantly reduce the glycated hemoglobin levels [11]. However, there are no previous reports on glycation reversing potential of fenugreek seed. Present study is the first study to report the presence of both anti-glycation and glycation reversing activities in fenugreek seed. Thus, findings indicate the potential use of fenugreek seed in ameliorating various diabetes complications [8,23].

Oxidative stress and protein glycation is closely related and tightly linked under hyperglycemic conditions in diabetic patients $[20,24]$. Several studies have shown that oxidative stress increases the rate of formation of advanced glycation end products. AGEs have the propensity to generate reactive oxygen species and further accelerate the protein glycation under hyperglycemic conditions in diabetic patients $[6,20,24]$. Thus, combat of oxidative stress is one of the therapeutic approaches in treating diabetic patients [24]. It is reported that AGEs associated pathologies of diabetes complications can be treated effectively using synergistic action of compounds offering both anti-glycation and antioxidant properties [24,25]. In the present study seed extract of fenugreek had antioxidant activity via radical scavenging (ABTS \& DPPH: $35.45 \pm 0.32$ and $28.13 \pm 0.76$ mg Trolox equivalents/g extract respectively) and reducing power (21.06 \pm 0.42 Trolox equivalents/g extract). Previous studies have reported seed extract of fenugreek had antioxidant activity via multiple mechanisms and such mechanisms include radical scavenging, reducing power, inhibition of lipid per oxidation, carbonyl trapping and metal ion chelation [26,27].

Anti-glycation activity of natural products including spices and condiments has strong correlation with antioxidant activity $[24,28]$. Therefore observed anti-glycation activity o fenugreek seed extract in the present study may be at least partly due to its anti-oxidant activity. In contrast polyphenols a group of secondary metabolites with diversified phytochemical classes such as flavones, flavanones, flavones, is flavones and proanthocyanidins. These compounds are reported to have anti glycation activity in several in vitro and in vivo studies $[20,28]$. Polyphenols reported to exert anti-glycation activity through multiple mechanisms such mechanisms include radical scavenging, carbonyl trapping, metal iron chelation, protein interaction and blocking the receptor for advanced glycation end products (RAGE) [20,25]. Fenugreek seed extract in the present study had total phenolics (43.67 $\pm 2.85 \mathrm{mg}$ Gallic acid equivalents/g extract) particularly as flavonoids $(25.25 \pm 0.91 \mathrm{mg}$ quercetin equivalents/g extract). It is reported that among various classes of polyphenolic dietary flavonoids possesses the highest potential for the inhibition of glycoxidation with strong antioxidant activity [20]. Considering all, it can be hypothesized that observed anti-glycation and glycation reversing ability of seed extract of fenugreek may be at least partly due to its polyphenolis exerting antioxidant properties. Interestingly, this is the first study to report glycation reversing ability of seed extract of fenugreek and indicates its potential in managing AGEs associated pathologies in diabetes patients.

\section{Conclusion}

It is concluded that seed extract of fenugreek had both antiglycation and glycation reversing activities in BSA-glucose glycation model. Interestingly, glycation reversing activity of fenugreek seed is a novel finding for the anti-diabetic properties of fenugreek and indicates potential use in managing advanced glycation end products associated pathologies in diabetic patients.

\section{References}

1. (2015) American Diabetes Association, 2015 Classification and Diagnosis of Diabetes. Diabetes care 38: S8-S16.

2. (2013) International Diabetes Federation, 2013 Diabetes Atlas, (6 $6^{\text {th }}$ Edn.). Brussels, Belgium.

3. Wild S, Roglic G, Green A, Sicree R, King H (2004) Global prevalence of diabetes: estimates for the year 2000 and projections for 2030. Diabetes Care 27(5): 1047-1053.

4. (2017) nternational Diabetes Federation 2017, Diabetes Atlas, ( $8^{\text {th }}$ Edn.). Brussels, Belgium.

5. Sharma C, Kaur A, Thind SS, Singh B, Raina S (2015) Advanced glycation End-products (AGEs): an emerging concern for processed food industries. J Food Sci Technol 52(12): 7561-7576. 
6. Singh VP, Bali A, Singh N, Jaggi AS (2014) Advanced Glycation End Products and Diabetic Complications. Korean J Physiol Pharmacol 18: $1-14$.

7. Negre Salvayre A, Salvayre R, Augé N, Pamplona R, Portero Otín M (2009) Hyperglycemia and glycation in diabetic complications. Antioxid Redox Signal 11(12): 3071-3109.

8. Reddy VP, Beyaz A (2006) Inhibitors of the Maillard reaction and AGE breakers as therapeutics for multiple diseases. Drug Discov Today 11: 646-654.

9. Yadav UC, Baquer NZ (2014) Pharmacological effects of Trigonella foenum-graecum L. in health and disease. Pharm Biol 52(2): 243-254.

10. Olaiya CO, Soetan KO (2014) A Review of the Health Benefits Of Fenugreek (Trigonellafoenum-graecum L.): Nutritional, Biochemical and Pharmaceutical Perspectives. AJSIH ISSN: 2276-6928.

11. Srinivasan K (2006) Fenugreek (Trigonella foenum-graecum): A Review of Health Beneficial Physiological Effects. Food Rev Int 22(2): 203-224.

12. Matsuura N, Aradate T, Sasaki C, Kojima H, Ohara M (2002) Screening system for the Maillard reaction inhibitor from natural product extracts. J Health Sci 48: 520-526.

13. Premakumara GAS, Abeysekera WKSM, Ratnasooriya WD, Chandrasekharan NV, Bentota AP (2013) Antioxidant, anti-amylase and anti-glycation potential of brans of some Sri Lankan traditional and improved rice (Oryza sativa L.) varieties. J Cereal Sci 58(3): 451-456.

14. Singleton VL, Orthofer R, Lamuela-Raventos RM (1999) Analysis of total phenols and other oxidation substrates and antioxidants by means of Folin-Ciocalteu reagent. Methods Enzymol 299: 152-178.

15. Siddhuraju P, Becker K (2003) Antioxidant properties of various solvent extracts of total phenolic constituents from three different agro climatic origins of drumstick tree (Moringa oleifera Lam.) leaves. J Agric Food Chem 51: 2144-2155.

16. Benzie IFF, Szeto YT (1999) Total antioxidant capacity of teas by the ferric reducing/antioxidant power assay. J Agric Food Chem 47(2): 633636.

17. Blois MS (1958) Antioxidant determinations by the use of a stable free radical. Nature 181: 1199-1200.
18. Re R, Pellegrini N, Proteggente A, Pannala A, Yang M (1999) Antioxidant activity applying an improved ABTS radical cation decolorization Assay. Free Radic Biol Med 26: 1231-1237.

19. Arachchige SPG, Abeysekera WPKM, Ratnasooriya WD (2017) Antiamylase, anti-cholinesterases, anti-glycation and glycation reversing potential of bark and leaf of Ceylon cinnamon (Cinnamomum zeylanicum Blume) in vitro. Evid Based Complement Alternat Med 35: 1-13.

20. Yeh WJ, Hsia SM, Lee WH, Wu CH (2017) Polyphenols with antiglycation activity and mechanisms of action: A review of recent findings: Review Article. J Food Drug Anal 25: 84-92.

21. Anonymous (2002) Talpatha Osu Mahima: Extracted from ancient Sri Lankan palm leaf manuscripts/Ola leaf writings. Volume I, II, III, Department of Ayurveda, Bandaranayake Memorial Ayurvedic Research Institute: Deepani Publishers Pvt Ltd, Sri Lanka.

22. Moniruzzaman M, Parengkuan L, Yagi M, Yonei Y (2015) Effect of proteins, sugars and extraction methods on the anti-glycation activity of spices. Glycative Stress Res 2(3): 129-139.

23. Degroot J (2004) The AGE of the matrix: chemistry, consequence and cure. Curr Opin Pharmacol 4(3): 301-305.

24. Ramkissoon JS, Mahomoodally MF, Ahmed N, Subratty AH (2013) Antioxidant and anti-glycation activities correlates with phenolic composition of tropical medicinal herbs. Asian Pac J Trop Med 6(7): 561-569.

25. Zhang X, Chen F, Wang M (2014) Antioxidant and Anti-glycation Activity of Selected Dietary Polyphenols in a Cookie Model. J Agric Food Chem 62: 1643-1648.

26. Dixit P, Ghaskadbi S, Mohan H, Devasagayam TPA (2005) Antioxidant Properties of Germinated Fenugreek Seeds. Phytother Res 19: 977-983.

27. Bukhari SB, Bhanger MI, Memon S (2008) Antioxidative Activity of Extracts from Fenugreek Seeds (Trigonella foenum-graecum). Pak J Anal Environ Chem 9(2): 78-83.

28. Dearlove RP, Greenspan P, Hartle DK, Swanson RB, Hargrove JL (2008) Inhibition of Protein Glycation by Extracts of Culinary Herbs and Spices. J Med Food 11(2): 275-281.

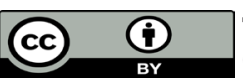

This work is licensed under Creative Commons Attribution 4.0 License

Submission Link: https://biomedres.us/submit-manuscript.php

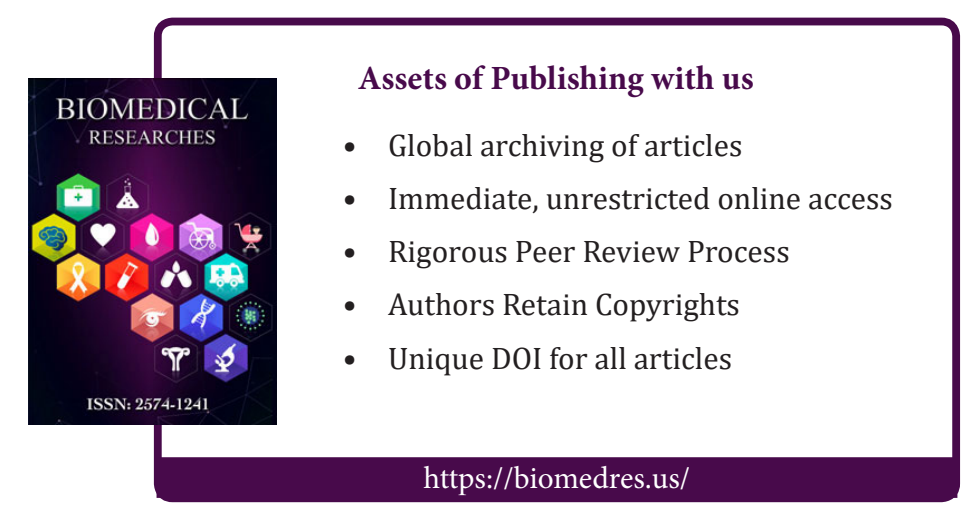

